\title{
ATRAINDO EUROPEUS: A PROVÍNCIA DO PARANÁ ATRAVÉS DE UM GUIA PARA EMIGRANTES DO SÉCULO XIX
}

\author{
Victor Gustavo de Souza ${ }^{1}$
}

\begin{abstract}
Resumo: Com do fim do tráfego negreiro intercontinental (1850), o Brasil deu um tímido, mas significativo, passo para o fim da escravidão, que foi sucedido por diversas outras medidas abolicionistas. Enquanto a escravidão se mostrava cada vez mais incerta, o elemento humano cada vez mais necessário. Curiosamente, na Europa sua população aumentava e causava crises de abastecimento e produção de gêneros alimentícios. Dessa relação, temos a perfeita combinação para o desenvolvimento de um fluxo migratório internacional. Diversas medidas foram tomadas visando atrair imigrantes, tanto pelo governo como por particulares, aqui destacamos a massiva campanha publicitária empreendida na Europa. Como ferramenta dessa campanha, temos os chamados guias para emigrantes: manuais que buscavam apresentar as vantagens de determinado local e convencer o possível migrante a estabelecer-se em suas terras. Neste artigo discutiremos, portanto, como a província do Paraná foi retratada em um desses guias, publicado em 1875, e distribuído pela Europa.
\end{abstract}

Palavras-chave: Propaganda imigratória. Guia para emigrantes. Província do Paraná.

\section{ATTRACTING EUROPEANS: THE PROVINCE OF PARANA THROUGH A GUIDE FOR EMMIGRANTS FROM THE NINETEENTH CENTURY}

\begin{abstract}
With the end of the intercontinental slave trade (1850), Brazil gave a shy, but significant, step towards the end of slavery, which was succeeded by several other abolitionist bills. As slavery became increasingly uncertain, the human element was increasingly needed. Interestingly, in Europe its population was increasing and causing crises of supply and production of foodstuffs. From this relationship, we have the perfect combination to establish an international migratory flow. Various measures had been taken to attract immigrants, both by the Government and private individuals, here we highlight the massive propaganda campaign undertaken in Europe. As a tool of this propaganda, we have the so-called guides for emmigrants: manuals that sought to present the advantages of Brazil or a certain province and convince the possible migrant to settle in Brazilian lands. In this article we will discuss how the province of Paraná was portrayed in one of these guides, published in 1875, and distributed throughout Europe.
\end{abstract}

Keywords: Immigration propaganda. Guide for emmigrants. Province of Paraná.

\section{Introdução}

A imigração, tema tão carente à sociedade brasileira, possui uma vasta e profusa literatura, feita a partir de diferentes olhares e fontes. Mesmo assim, ainda conseguimos nos

\footnotetext{
${ }^{1}$ Mestrando em História pela Unesp, campus de Assis, linha Política: Ações e Representações, possui graduação em História pela mesma instituição. Contato: victor.assuntosacademicos@ gmail.com
} 
depararmos com fontes pouco exploradas, que permitem novos olhares sobre o assunto. Com isso em mente, neste artigo adotamos como objeto de estudo um guia para emigrantes do século XIX sobre a província do Paraná.

Em linhas gerais, podemos conceber esse tipo de fonte como manuais voltados para migrantes que buscavam conhecer melhor seu possível destino. Esse tipo de material funcionou como aparato da política imigratória do século XIX, não apenas do Brasil, mas também de outros países do continente americano. Cada manual tinha um objetivo específico: expor determinado local (país, império, províncias e estados, por exemplo); as suas vantagens; suas belezas e oportunidades para aqueles que cogitavam deixar sua pátria e, através de sua narrativa, convencê-los a se afixarem nas terras em questão.

Desde a época joanina tentativas para introduzir o imigrante no Brasil já começavam a aparecer nos planos do governo, fato que teria início com a promulgação do decreto de 25 de novembro de 1808 , onde D. João autorizava todos os estrangeiros residentes no Império Brasileiro tornarem-se proprietários de terras. Segundo Manfroi, o príncipe regente pretendia com sua política imigratória fornecer bases para que o Brasil pudesse avançar em seus mais variados setores (econômico, social e político), além de modernizar o pensamento da sociedade brasileira ${ }^{2}$.

A partir de então, diversas experiências foram empreendidas na atração do estrangeiro $^{3}$, no entanto, podemos entendê-las apenas como atividades pontuais, visto que, na prática, não produziram um fluxo imigratório contínuo. Não seria até a década de 1880 , no auge da crise escravista e da tão divulgada falta de mão de obra que milhares de europeus passariam a entrar em nossas fronteiras.

Essa distância de quase oito décadas nos revela alguns pontos sobre o Brasil Imperial: primeiramente, percebe-se a falta de uma política forte e direcionada para a imigração; em um segundo momento, as elites pressionando o governo para a manutenção da escravidão; e, ainda, quando algumas tentativas pareciam vingar, elas malogravam por variados fatores, desde a mentalidade escravista de fazendeiros, que não conseguiam perceber o imigrante

\footnotetext{
${ }^{2}$ MANFROI, Olívio. A colonização Italiana no Rio Grande do Sul. Implicações Econômicas, Políticas e Culturais. Porto Alegre: Fotogravura do Sul Ltda, 1975, p. 21.

${ }^{3}$ Não nos adentraremos nessas tentativas, visto a vasta bibliografia existente. Cf.: BEIGUELMAN, Paula. A formação do povo no complexo cafeeiro: aspectos políticos. São Paulo: Pioneira, 1968; MENDES, José Sacchetta Ramos. Desígnios da Lei de Terras: imigração, escravismo e propriedade fundiária no Brasil Império. Salvador, 2009; LAMOUNIER, Maria L. Da escravidão ao trabalho livre (A lei de locação de serviços de 1879). Campinas, SP: Papirus. 1988
} 
Revista NEP - Núcleo de Estudos Paranaenses, Curitiba, v.5, n.1, jun. 2019

como um parceiro, até a insatisfação dos imigrantes que se sentiam enganados. Este último fator, está diretamente relacionado com os guias para emigrantes, uma vez que, no intuito de apresentar províncias, países e impérios, muitas vezes, os discursos adotados se tornavam eloquentes e até enganosos.

Neste artigo, analisamos um guia sobre o Paraná, datado de 1875, intitulado "Província do Paraná: Dados Estatísticos e Esclarecimentos para os Emigrantes"4. Composto por 141 páginas enumeradas, anexos e um mapa, este material encontra-se disponível nos arquivos digitalizados da Biblioteca Brasiliana Guita e José Mindlin ${ }^{5}$ e da Biblioteca Digital Luso-Brasileira ${ }^{6}$. Como veremos, o opúsculo discorre sobre variadas informações acerca da província paranaense, indo desde clima até favores e vantagens; de colônias para imigrantes à religião, tudo reunido em um só material a ser distribuído pela Europa.

\section{Por trás dos Esclarecimentos}

Esclarecimentos para imigrantes inicia destacando a posição vantajosa do Paraná, de fácil comunicação com outras localidades e saída para o oceano. Declara que "Basta attender a estes limites para reconhecer que a provincia do Paraná é destinada a servir de emporio a um commercio interprovincial e internacional da maior importância"7, também faz comparações em relação a sua extensão, afirmando ser maior que o território da Inglaterra, Escócia e Irlanda juntos. Todavia, antes de nos aprofundarmos nas questões internas do guia, faz-se necessário compreender, mesmo que em linhas gerais, alguns de seus elementos externos, como o momento de publicação e aqueles que estiveram à sua frente.

Durante o ano de sua divulgação, estiveram à frente do ministério os senhores José Fernandes da Costa Pereira Júnior (de 28 de janeiro de 1873 até 25 de junho de 1875) e Tomás José de Coelho de Almeida (entre 25 de junho de 1875 até 05 de janeiro de 1878) ${ }^{8}$. A partir destas balizas temporais, atentamo-nos em buscar indícios em nossa fonte que

\footnotetext{
${ }^{4}$ PARANÁ. Provincia do Paraná, dados estatisticos e esclarecimentos para os emigrantes. Rio de Janeiro: G. Leuzinger \& Filhos, 1875.

${ }^{5}$ Disponível em: https://digital.bbm.usp.br/handle/bbm/5050. Acesso em: 12 de fev. 2019.

${ }^{6}$ Disponível em https://bdlb.bn.gov.br/redeMemoria/handle/123456789/305432. Acesso em: 12 de fev. 2019.

${ }^{7}$ PARANÁ, op. cit., p. 06. Todas as transcrições serão feitas de acordo com grafia do original

${ }^{8}$ GABLER, Louise. A secretaria de Estado dos Negócios da Agricultura, Comércio e Obras Públicas

e a modernização do Império (1860-1891). Rio de Janeiro: Arquivo Nacional, 2012, p. 111.
} 
apontassem qual o ministro em exercício à época e, através desse exercício, foi possível concluir que Coelho de Almeida encabeçava o gabinete, ao passo que o livreto contém passagens posteriores a junho de $1875^{9}$.

Filho de Custódio José Coelho de Almeida e Da Maria Theresa da Rosa, ambos portugueses vindos para o Brasil junto com a Corte Portuguesa por ocasião da ação das tropas francesas comandadas pelo General Junot (1808), Almeida nasceu em 27 de dezembro de 1837, na cidade de Campos dos Goitacazes. Graduou-se em Ciências Jurídicas e Sociais, onde passou a exercer o magistério de volta em sua cidade, contudo seria na vida política que trilharia seus principais caminhos. De vereador a Senador, Coelho de Almeida ocupou diversos cargos públicos, sendo convidado por Duque de Caxias para estar à frente do Ministério dos Negócios da Agricultura, Comércio e Obras Públicas, em 1875, onde permaneceria por dois anos e seis meses. Foi, também, um dos responsáveis pela criação da Inspetoria de Terras e Colonização e, em 1888, escolhido pela Princesa Isabel para ocupar a uma cadeira no Senado. Encabeçou, ainda, os ministérios da Guerra e da Marinha. Sua vida encerrou-se em $1895^{10}$.

Nesse momento voltaremos nossas atenções para o Ministério dos Negócios da Agricultura, Comércio e das Obras Públicas (ou SENACOP ${ }^{11}$ ), a fim de melhor entender seu funcionamento e seus objetivos. Sua criação, em 28 de julho de 1860, esteve relacionada à diversas situações vigentes no Império e existiria até 1891, passando a ser Ministério da Indústria, Viação e Obras Públicas. A SENACOP ficou encarregada de inúmeras atividades heterogêneas que se encontravam divididas em quatro categorias: 1) Central e dos Negócios da Agricultura, Comércio e Indústria; 2) de Obras Públicas e Navegação; 3) das Terras Públicas e Colonização; 4) dos Correios ${ }^{12}$.

Louise Gabler afirma que até o ano de sua fundação, o Estado possuía apenas seis secretarias, que se equivaliam aos posteriores "ministérios", ele também diz que a estrutura administrativa do Brasil "era muito simplificada" e que, portanto, não havia grandes divisões

\footnotetext{
${ }^{9}$ PARANÁ, op. cit., p. 84, 88, 92, 93, 104. A partir dessas informações, poderíamos inferir que o guia teria sido publicado em algum momento do último trimestre de 1875 , porém o mapa localizado ao final é datado de 1876. Essa divergência pode sugerir que a produção da obra tenha começado em 1875 e só distribuído no ano seguinte.

${ }^{10}$ Texto elaborado a partir das informações disponíveis no endereço eletrônico: < https://goo.gl/Y6KRi3>. Acesso em 05 fev. 2019.

${ }^{11}$ Em alguns trabalhos esse mesmo órgão recebe o nome de Secretaria de Estado dos Negócios da Agricultura, Comércio e Obras Públicas e a modernização do Império (SENACOP). Em nosso texto passaremos a utilizar sua sigla.

${ }^{12}$ GABLER, op. cit., p. 11
} 
Revista NEP - Núcleo de Estudos Paranaenses, Curitiba, v.5, n.1, jun. 2019

de afazeres ${ }^{13}$. Em determinado momento, o gerenciamento interno imperial tornou-se mais burocrático e ocorreram divisões e reformas na Secretaria, mesmo assim suas atribuições continuaram diversificadas e à frente de assuntos privilegiados para o Governo Central, como a agricultura.

Roberta Meira credita a criação do Ministério/Secretaria às questões relacionadas à agricultura, pois, segundo a autora, os relatórios desse órgão e dos presidentes das províncias indicam "uma série de dificuldades enfrentadas pela grande lavoura brasileira"14. Desse modo, medidas que valorizassem a defesa de políticas voltadas aos interesses da agricultura deveriam ser tomadas, tanto pelas províncias quanto pelo Governo Central, e a criação da SENACOP seria um reflexo dessa preocupação. Em suas palavras,

podemos encontrar de forma tão recorrente nos documentos deixados tanto pelo Ministério dos Negócios da Agricultura, Comércio e Obras Públicas quanto pela Presidência da Província tal sorte de interesses econômicos, sociais e políticos convergentes. Motivos havia para que a crise da lavoura provocasse certos temores. Assim, nada mais natural que o Estado viesse em socorro de quem o sustentava ${ }^{15}$.

Enquanto Gabler defende que a modernidade da segunda metade do século XIX, trazida pela Segunda Revolução Industrial, exigia um "aparato administrativo que pudesse fomentar e regular esse processo" ${ }^{16}$, Meira, por sua vez, enxerga a criação do órgão como uma resposta à agenda governamental relacionada à economia. Analisando esses dois olhares e relacionando-os com nosso objeto, a posição defendida por Meira nos parece mais adequada, posto que a autora coloca a agricultura como força motriz para o progresso, e não o contrário.

Em vista disso, pode-se dizer que a SENACOP esteve, desde seu início, preocupada com o principal meio de renda do Império: a agricultura. Levando esse pressuposto em consideração, “Esclarecimentos para os Emigrantes..." serve a diferentes objetivos: em um primeiro olhar, funcionou como propaganda imigratória, um manual voltado a potenciais imigrantes com o desejo de tentar uma nova vida além-mar; mas, de maneira mais

\footnotetext{
${ }^{13}$ Ibid., p. 11.

${ }^{14}$ MEIRA, Roberta B. "Um olhar para a lavoura: os relatórios do Ministério dos Negócios da Agricultura, Comércio e Obras Públicas e dos Presidentes de Província no final do Império". Revista Eletrônica Documento/Monumento, 2009, v.1, p. 110.

${ }^{15}$ Ibid., p. 112.

${ }^{16}$ GABLER, op. cit., p. 12.
} 
aprofundada, a propaganda se configura como uma ferramenta das políticas voltadas à proteção e estabilidade da agricultura.

Essa hipótese encontra respaldo em uma das falas de Tomás Coelho, ministro responsável pelo guia, onde ele discorre sobre os problemas enfrentados pela agricultura no país, assinalando a dificuldade em fornecer crédito para os homens da terra e traz para debate o problema do trabalho escravo e a mão de obra imigrante.

\begin{abstract}
Considerada, desde os primeiros seculos, a profissão mais util e digna do homem livre, a agricultura, principal fonte da riqueza publica e privada no Imperio, tem direito á mais decidida proteção dos poderes publicos. É certo que depois do Decreto n. 1067 de 28 de julho de 1860 podemos tambem repetir que o Estado reconheceu tanto a importância desta industria, que the deu na alta administração do paiz o mesmo lugar que á Justiça, ao Exercito e ás Finanças ${ }^{51}$.
\end{abstract}

Este trecho deixa claro sua posição de defesa dos interesses relacionados à agricultura, classificando tal ocupação como a mais digna e colocando-a ao lado do exército e da própria justiça. Dito isto, podemos seguir em frente e voltarmos nossas atenções para o interior de nossa fonte. A seguir exploramos alguns pontos que nos pareceram de maior relevância dentro do documento, afinal, não seria possível explorá-lo de maneira integral, visto os limites físicos de um texto-artigo.

\title{
Clima e agricultura: salubridade e prosperidade
}

A questão do clima se mostra como um importante tema para o material. Além de dados numéricos sobre temperaturas e afins, o guia faz uso de relatórios de expedição de personagens como André Rebouças e William Lloyd para corroborar com suas declarações ou apenas para ilustrá-las. Devido a variabilidade de seu clima, a publicação deixa claro que é necessário dividir a província paranaense em seis diferentes regiões, pois poderiam influenciar na escolha do imigrante:

Cada uma destas seis regiões tem o seu clima distincto. Estes climas estão por assim dizer graduados desde o mais quente — o da Marinha ou do Beira Mar —, até ao mais frio, o do planalto de Curitiba, que fica em altitude de 900 a mil metros; desde o mais humido - o da Serra do Mar, onde os vapores do Oceano Atlantico vêm se condesar como de encontro a uma muralha fria, e formam chuvas muito frequentes, até ao mais secco — o dos mais altos pontos do planalto de Curitiba ${ }^{17}$.

${ }^{17}$ PARANÁ, op. cit., p. 24. 
A existência de diferentes climas é registrada como algo positivo, tanto para a província quanto para os imigrantes, visto que essa condição permitiria desde o cultivo de gêneros europeus, adaptados a climas mais frios, até a produção de artigos tropicais, como cana-de-açúcar e café. Marlon Salomon salienta que o clima em si, não era fonte de preocupação, mas a sua ação nas plantas, animais e no homem, levantando questionamentos como a viabilidade na vinda de imigrantes europeus para as regiões tropicais; sua adaptação ou não ao clima; e a ação do clima neles. Segundo o autor, é a partir dessa problemática que ocorre "a constituição de um espaço, de uma nova realidade, digamos, biogeográfica, chamada de sul do Brasil"18.

A criação dessa região, por assim dizer, não se tratava apenas de uma modificação nominal. Esperava-se que "se fale do sul do Brasil como uma região constituída e dotada de uma identidade não mais com um atributo político-militar, mas sim de acordo com a salubridade do seu clima"19. A recém-criada região sul buscava se distanciar do Brasil (ou ao menos de seu clima tropical), a fim de que suas políticas imigratórias não fossem afetadas pelas ideias em voga na época de que regiões tropicais eram, basicamente, sinônimo de morte para os europeus.

Importante lembrar que, durante o século XIX e especialmente a partir de sua segunda metade, as epidemias foram uma constante não só no Brasil, como nos demais países da Bacia do Prata. No Império Brasileiro, a cólera morbus e a febre amarela foram as principais moléstias que assolaram diversas províncias. Diante dessa situação, foi criada no Rio de Janeiro, em 1850, a Junta Central de Higiene Pública que, além ser responsável pela inspeção de diversos locais da cidade, devia "aconselhar e formular as políticas de atuação do governo imperial na área de saúde pública" ${ }^{20}$.

Segundo Chaves, o fato de as próprias autoridades de saúde não saberem como lidar com as epidemias e as centenas de mortes que estas causavam, não podendo auxiliar a

\footnotetext{
${ }^{18}$ SALOMON, Marlon. "O clima, a Imigração e a Invenção do Sul do Brasil no século XIX”. In: ARRUDA, Gilmar (org.). Natureza, fronteiras e território. Londrina: Eduel, 2013, p. 98.

${ }^{19}$ Ibid., p. 104, grifo nosso.

${ }^{20}$ CHALHOUB, Sidney. Cidade febril: cortiços e epidemias na Corte imperial. São Paulo: Companhia das Letras, 1996, p.66.
} 
população com medidas profiláticas, causou medo e inseguranças nas pessoas, desde as classes mais abastadas até os miseráveis ${ }^{21}$.

Chalhoulb apontou que, durante toda a década de 1870, momento em que nosso objeto está inserido, o Brasil passava por uma crise pública de saúde com a febre amarela, tendo se constituído, inclusive, como um dos principais entraves para o processo político imigratório em curso $^{22}$.

O problema aqui é claro: como atrair o imigrante para um local tomado por doenças? Se tal situação não fosse resolvida, a política imigratória ainda embrionária, teria sérias complicações. De fato, a saúde pública precária levou a campanhas "anti-imigratórias" para o Brasil. A Prússia, por exemplo, proibiu em 1859 a imigração para São Paulo e, posteriormente, em 1871, estendeu sua decisão para todo o Império ${ }^{23}$.

A questão da saúde fica clara no tópico "Salubridade", que inicia com a afirmação de que o clima do Paraná é um dos mais saudáveis do mundo, conhecido em todo o Brasil, quase como um "provérbio", e se encerra com a passagem

Pódem, pois, os emigrantes ter a certeza que encontrarão na provincia do Paraná as melhores condições de salubridade; um clima muito analogo ao do Norte da Italia; os mesmos alimentos e todas as felicidades possíveis para sua acclimação ${ }^{24}$.

A partir desse panorama, a região Sul do Brasil, "passa a estar associada a um clima saudável", como destaca Salomon, "distinto daquele dos trópicos"25. Diante disso, pode-se entender que a extensão do tema (ocupando por volta de dez páginas) e a adição de diversos relatos sobre as boas condições climáticas da província estão ligadas ao combate das ideias de determinismo climático e à defesa do Império em sua busca por emigrantes.

Esse pensamento seria levado adiante durante décadas de política imigratória e, percebendo a necessidade de se distanciar dos trópicos, em determinado momento o clima sulista passou a representar o clima de todo o Brasil nas propagandas. Além de representar qualidade de vida, ele também significava boa produção na agricultura:

\footnotetext{
${ }^{21}$ CHAVES, C. L. "Epidemias e imigração: as relações internacionais entre o Império do Brasil e as repúblicas platinas na segunda metade do século XIX”. Anais do XXIII Simpósio Nacional de História: história, guerra e paz. Londrina: Editorial Mídia, 2005, p. 02

${ }^{22}$ CHALHOUB, op. cit., p. 29.

23 REZNIK, Luís; FERNANDES, Rui A. N. "Hospedarias de Imigrantes nas Américas: a criação da hospedaria da Ilha das Flores”. História. Franca, 2014, v. 33, n. 1, p. 240.

${ }^{24}$ PARANA, op. cit., p. 33.

${ }^{25}$ SALOMON, op. cit., p. 105.
} 
O clima, conveniente para o desenvolvimento do pinho brasileiro (Araucaria Brasilianna), é tambem o mais favorável para os cereais e para as batatas. Tambem neste clima produzem abundantemente os fructos europeus, taes como as maçãas (Malus communis); as pêras (Pyrus communis); os pecegos (Persica vulgaris); os morangos (Fragaria vesga), etc. etc ${ }^{26}$.

Frente à tamanha variedade de produção, podemos, agora, dar início a um dos principais capítulos de Esclarecimentos: a agricultura, seção mais extensa da brochura, com dezenove páginas, onde apresenta uma série de artigos produzidos na província e as vantagens que os imigrantes poderiam ter caso optassem por uma cultura ou por outra.

Assunto que sempre se mostrou importante em nossas análises, a agricultura de uma região basicamente determinaria o modo de vida de seus habitantes, nacionais ou não, afinal, apesar da chegada do trem e do germe da industrialização, o Brasil ainda era rural, por consequência, a fertilidade da terra importava; o que essa terra produzia importava; o quanto essa terra produzia importava.

A subvenção de passagens, o alojamento em hospedarias ou mesmo o clima devem ser encarados como fatores importantes nas políticas de atração, contudo, a agricultura e fertilidade do solo ainda se mostravam como os fatores centrais dessas medidas (fossem elas voltadas para povoar as terras e assentar imigrantes em núcleos coloniais ou para assentálos em fazendas cafeeiras).

Dessa maneira, o guia dedica uma porção a descrever as principais culturas do Paraná, algumas com mais outras com menos informações, mas sempre atestando as múltiplas possibilidades que o emigrante encontraria para se dedicar. Demonstrando a grande importância do assunto, declara:

Será, por certo, a agricultura a principal fonte de riqueza e de prosperidade dos immigrantes na provincia do Paraná.

Pela descripção, que temos feito, das condições naturaes desta Provincia, já se terá reconhecido que não é possivel reunir mais vantagens no solo, no clima e na capacidade para receber uma excelente rêde de viação. [...]

Para resumir em uma só palavra as producções desta Provincia é preciso dizer que o Paraná prodúz simultaneamente tudo quanto prodúz a Italia e tudo quanto prodúz a ilha de $\mathrm{Cuba}^{27}$

\footnotetext{
${ }^{26}$ PARANÁ, op. cit., p. 28-29.
}

${ }^{27}$ Ibid., p. 44. 
O excerto ilustra de maneira clara a questão acima: a agricultura como ponto principal da propaganda. Não apenas o material propagandístico se preocupa em construir uma narrativa sobre a província, ela busca colocá-la acima de outras regiões através de comparações, como explícito no último parágrafo, ao proclamar que a província paranaense era mais produtiva que um país do Velho Mundo e uma importante ilha de plantation do Novo Mundo.

Ainda em relação à agricultura, temos uma passagem curiosa sobre o café. Este produto não fazia parte da realidade paranaense na década de 1870 , seria apenas nos anos finais do Oitocentos que a onda verde começaria se dirigir para o norte do Paraná e, mais especificamente, com as políticas de restrição do plantio do café em São Paulo, $1902^{28}$, todavia, ele não é ignorado pelo guia.

Em determinado momento, a publicação enumera as maiores províncias produtoras deste artigo, na seguinte ordem: Rio de Janeiro, São Paulo; Bahia; Ceará; Minas Gerais; Pernambuco e Espírito Santo $^{29}$. Nota-se que o Paraná não aparece em nenhuma dessas posições e, mesmo assim, são dedicadas sete páginas à discussão do café. Além disso, essa é a única seção que debate sobre dados concernentes a outras localidades, no caso São Paulo e Rio de Janeiro. Em relação à província paranaense, não há grandes aspectos a ser debatido, apenas assegura que ações visando o avanço dessa cultura na região estavam em curso ${ }^{30}$.

Acreditamos que a inserção dessa discussão sobre o "ouro verde" talvez funcionasse como um mecanismo de atração indireta para o imigrante, pois, já em 1875, o café atingia números altos ou, considerando ser este um lançamento oficial do Império, o capítulo serviu como um meio de divulgar, mesmo que de maneira abrangente, que outras partes do território brasileiro desfrutavam de igual prosperidade. $\mathrm{O}$ fato é que, mesmo o café não sendo tradicional no Paraná, ele desfrutava de uma posição confortável o suficiente na vida econômica do Império para ser retratado no opúsculo.

À medida que o café não desempenhava papel significativo na economia paranaense, a erva-mate ocupava o posto de importante cultura da província e, apesar de sua relevância para a região, o material dedica apenas duas páginas para discutir o assunto. $\mathrm{O}$ livreto frisa o valor da erva para a América do Sul e seus crescentes índices de exportação, onde o Paraná

\footnotetext{
${ }^{28}$ PRIORI, A., et al. História do Paraná: séculos XIX e XX [online]. Maringá: Eduem, 2012, p. 93.

${ }^{29}$ PARANÁ, op. cit., p. 51.

${ }^{30}$ Ibid., p. 51.
} 
encontrava-se no topo como a principal província exportadora do Brasil, seguida do Rio Grande do Sul. No período financeiro de 1871-72, a província exportou 16.339,974 quilogramas de erva, o que rendeu um faturamento de 3.860:563\$000 réis ${ }^{31}$.

Adentrando, brevemente, nos procedimentos da produção e beneficiamento da erva, o guia atesta que, no geral, os imigrantes não encontrariam problemas, sendo esta uma atividade "muito simples".

\footnotetext{
A preparação do matte é muito simples, e lembra a do chá. Depois de colhidos, as folhas e os tenues talos vão ao fogo sofrer uma ligeira torrefacção; são depois socados em pilões, movidos por agua ou a vapor. [...]

Póde-se também perfurmar o matte com a Oleá flagrans, como os chinezes perfumam o chá, e tornal-o assim mais apetecível ${ }^{32}$.
}

Maccari Junior aponta que a utilização e consolidação do termo "erva" ocorreu devido a um engano de espanhóis ao avistarem aborígenes consumindo a iguaria que, prontamente, acreditaram ser uma espécie de erva. Segundo ele, "erva" é utilizado para designar "plantas arbustivas, não lenhosas", mas a erva-mate é uma árvore que não se encaixa nessa categoria, logo, "erva-mate" existe a partir desse engano histórico. O "mate", por sua vez, é uma palavra de origem indígena, mati, equivalente a cuia, recipiente ${ }^{33}$.

Magnus Pereira, no capítulo introdutório de "Semeando iras rumo ao progresso"34, chama a atenção para o surgimento da indústria ervateira na região paranaense e a consequente formação de uma burguesia fruto dessa indústria. Segundo o autor, o Paraná, durante toda a primeira metade do século XIX, configurava-se como uma província agrária, onde, além da exploração da erva-mate, a agricultura de subsistência e uma tímida pecuária eram responsáveis por grande parte da economia da região. E, apesar do cenário desfavorável, foi a partir dele que uma burguesia regional deu conta de "transformar os processos de produção do mate numa indústria bastante tecnificada" ${ }^{35}$.

Com o desenvolvimento dessa indústria, o Paraná passaria por diversas modificações, inclusive relacionado à urbanização, já que os processos relacionados à

\footnotetext{
${ }^{31}$ Ibid., p. 64.

${ }^{32}$ PARANÁ, op. cit., p. 65.

${ }^{33}$ MACCARI JUNIOR, Agenor. Análise do pré-processamento da erva-mate para chimarrão. Campinas, SP, 2005 , p. 4.

${ }^{34}$ PEREIRA, Magnus R. Semeando iras rumo ao progresso. Ordenamento jurídico e econômico da sociedade paranaense (1829-1889). Curitiba: UFPR. 1992.

${ }^{35}$ Ibid., p. 2.
} 
transformação da erva centravam-se nas cidades. Pereira problematiza a questão da urbanização, porque, à época, era difícil qualquer cidade da província conseguir concentrar um número elevado de habitantes, portanto, a aplicação do termo pode parecer equivocada. Todavia, para o autor, urbanização não está relacionada, exclusivamente, à quantidade de habitantes concentradas por metros quadrados, ele leva em conta a dinâmica socioeconômica da região focada nos centros urbanos, o que independe de seus tamanhos ${ }^{36}$. Essa característica urbana é retratada, ainda, como uma das motivações para a desagregação do escravismo na província e a criação de um mercado de trabalho essencialmente livre, se adiantando frente à crise do escravismo que se abateria sobre outras regiões, como São Paulo $^{37}$.

Conforme Fábio Moraes, a partir da segunda metade do século XIX, o mate começou a ocupar o posto de principal produto nas exportações das províncias sulistas brasileiras, o que resultou em uma rápida expansão e melhoria das técnicas empregadas na indústria ervateira. Apesar disso, esse não foi um mercado estável e, do mesmo modo como ocorreu com outros produtos tropicais brasileiros, sofreu oscilações que variaram ao longo de sua produção. A indústria estava sujeita ora a acontecimentos internos, como a Guerra do Paraguai, ora externos, ilustrado pela crise pós $1929^{38}$.

De fato, em meados do Oitocentos, notou-se um aumento dos preços do mate no mercado internacional, o que gerou uma expansão de engenhos pelo Paraná, com destaque para sua capital, Curitiba. Essa proliferação de engenhos, por sua vez, demonstra que um número cada vez maior de pessoas passou a se dedicar às atividades relacionadas ao mate, essa realidade teria como ônus uma crise de carestia nos gêneros de primeira necessidade da província $^{39}$.

Pereira, com o intuito de ilustrar as preocupações enfrentadas por habitantes da província frente à crise de gêneros de primeira necessidade, seleciona artigos de jornais, circulares e afins. A seguir, retiramos de sua publicação uma circular do Chefe de Polícia,

\footnotetext{
${ }^{36}$ Atrelada à questão da urbanização, temos estudos que desconsideram a indústria ervateira da época como verdadeiramente um processo industrial, pois foi encarada como uma "falsa indústria", voltada apenas para "um beneficiamento muito primário de um produto extrativo". Esses pensamentos, porém, não são compartilhados por Pereira, que defende ser a indústria do mate um modelo próximo ao "clássico manchestariano". Ibid., p. 09.

${ }^{37}$ Ibid., p. 04-05.

${ }^{38}$ MORAES, Fábio F. "Expansão do mercado e da produção: o auge do mate catarinense". Anais do VIII Encontro de Economia Catarinense. Rio do Sul (SC), 2014, v. 1, p. 02.

${ }^{39}$ PEREIRA, op. cit., p. 26.
} 
onde podemos perceber suas preocupações com a situação enfrentada pela província e suas recomendações aos delegados e policiais:

\begin{abstract}
que empregue todos os recursos de sua influência pessoal, e mesmo os da sua autoridade, dentro dos limites das suas atribuições, para conseguir dos moradores do seu distrito, que se não descuidem, no seu interesse próprio e comum utilidade, de plantar suas roças e tratar da criação daqueles animais de que a população costuma alimentar-se; fazendo-lhes V. S. ver, que esse mesmo enorme lucro, que os fascina e monopoliza a atenção para a erva-mate, tornar-se-á ilusório, fictício e insuficiente, quando a carestia dos gêneros alimentícios os obrigar a pagar por alto preço, o mantimento seu e das suas famílias ${ }^{40}$.
\end{abstract}

Datado de 1855, essa notícia é apenas um dos exemplos que podemos utilizar para asseverar a força que o mate havia adquirido na província paranaense, sua rentabilidade tão vantajosa havia se tornado um problema. Nota-se, então, um paralelo com a questão do café, na província paulista, onde a dedicação, quase que exclusiva, a um produto de exportação com bom retorno financeiro desestrutura a economia de subsistência da região e coloca em risco superlotar o mercado, ficando vulnerável a possíveis crises.

Frente a tal calamidade, a postura adotada pelo poder público modificou-se e a indústria do mate, outrora tão defendida, passou a sofrer diversas críticas. Essa rápida queda de popularidade ilustra as oscilações do artigo ao longo do século XIX, entretanto, não seria forte o suficiente para provocar modificações muito significativas e continuaria a ser o principal produto da província.

Entre altos e baixos, Esclarecimentos... encoraja os estrangeiros a se dedicarem às atividades relacionadas ao mate:

Os immigrantes encontrarão nas vastissimas florestas [...] da provincia do Paraná elementos para uma industria muito simples e muito lucrativa; poderão tambem, pela sua inteligência e atividade melhorar esse producto, e concorrer eficazmente para a sua introdução na Europa e nos Estados Unidos ${ }^{41}$.

\title{
Atrair para colonizar
}

Os termos "colono", "colônias" e "colonização" merecem atenção especial, uma vez que se fazem presentes por todo nosso texto. Segundo Manfroi, "no Brasil, o termo

${ }^{40}$ O Dezenove de Dezembro, Curitiba, 24 out.1855. p.4 apud PEREIRA, op. cit., p. 27

${ }^{41}$ Ibid., p. 65. 
colonização foi utilizado para definir o processo de 'derrubada da floresta, a valorização do território para fins agrícolas e o seu povoamento" "42, dessa forma, ele utiliza o vocábulo somente para indicar "a introdução de colonos estrangeiros (imigrantes) para a valorização de terras incultas, sob direção do governo ou de particulares" ${ }^{\text {43 }}$. Com isso em mente, nos apoiaremos na definição de Manfroi quando utilizarmos tais vocábulos.

Ao passo que trabalhador estrangeiro se denominava colono para se distinguir socialmente do escravo, os fazendeiros, em contrapartida, ao chamar os parceiros de "colonos", tinham em mente algo bem distinto do sentido usado pelas sociedades de imigração e colonização: para a maioria dos fazendeiros "colono" significava servidão não escrava $^{44}$.

Tal como outras províncias do Império, o Paraná assumiu o compromisso de "preencher seus vazios" por meio da criação de várias colônias baseadas na pequena propriedade que, por sua vez, deveriam abastecer os mercados com alimentos. Deste modo, não é surpresa que o discurso do manual se dedique a apresentar alguns empreendimentos coloniais da província, sinalizando-os como bons destinos para os imigrantes se fixarem.

Ao analisar a forma como essas colônias são descritas no guia, percebemos que, apesar de não haver um padrão definido, aspectos como (i) nacionalidade dos habitantes; (ii) distância em relação a um grande centro (geralmente a capital da província); e (iii) principal cultura ou atividade econômica da colônia sempre se fazem presentes.

Essa constatação não é encarada como algo inesperado, visto que seria natural o imigrante optar por colônias com habitantes que compartilhassem a mesma língua e cultura; além de se preocupar com as atividades agrícolas que estaria sujeito a trabalhar, possibilidades de locomoção e venda de excedentes. Observando todos esses fatores, o futuro colono poderia escolher o destino que melhor lhe servisse.

Os capítulos finais dialogam diretamente com o emigrante, e no tópico Vantagens temos o seguinte enunciado: "São os estrangeiros acolhidos no Brasil com toda a benevolência, seus direitos respeitados, e, em suas relações civis amparadas pela proteção das leis”45. Essa passagem possui apenas duas páginas e dá uma rápida visão sobre os direitos

\footnotetext{
${ }^{42}$ MANFROI, op. cit., p. 9.

${ }^{43}$ Ibid., p. 14.

${ }^{44}$ LESSER, Jeffrey. A invenção da brasilidade. Identidade nacional etnicidade e políticas de imigração. São Paulo: Editora Unesp, 2015, p. 77.

${ }^{45}$ PARANÁ, op. cit., p, 107.
} 
dos imigrantes. Dentre as vantagens aponta-se: escolas gratuitas para os filhos dos estrangeiros e plena cidadania quando atingissem a maioridade; garantia de habeas corpus; reconhecimento de casamentos entre católicos e liberdade religiosa. Sobre a religião afirma: "Gozam da maior liberdade de consciência sem receio de serem perseguidos por motivos de religião, uma vez que respeitem a do Estado"46.

Vale lembrar que no ano de 1824 o Brasil promulgou sua nova Constituição, assumindo o compromisso com a imigração e, apesar de o catolicismo romano ainda permanecer a religião oficial do Império, o artigo quinto garantia a liberdade religiosa a qualquer um. De acordo com Campos, a questão religiosa foi alvo de intensos debates na imprensa durante a década de 1870, pois grande parte dos imigrantes que chegavam ao Brasil eram protestantes ou não católicos e as interferências da Igreja Católica nos núcleos coloniais causavam, muitas vezes, $\operatorname{conflitos}^{47}$.

Monteiro Mesquita destaca que um dos principais problemas para o imigrante não católico era a falta de reconhecimento de seu casamento perante o governo e que, além de esses imigrantes terem sua moral atacada, encontravam-se privados de "vários direitos decorrentes do contrato matrimonial" ${ }^{\prime 2}$. Angela Lima, por sua vez, alega que, mesmo com a liberdade de culto confirmada na Constituição, a intolerância religiosa e a invalidade dos casamentos civis configuraram-se como fatores de repulsão de estrangeiros do Brasil ${ }^{49}$.

"Favores aos Immigrantes" aparece como uma continuação de Vantagens, expondo os benefícios que o estrangeiro poderia obter caso se dirigisse para a província, dando destaque para o órgão responsável pelos assuntos imigratórios no Império: a Agência Oficial de Colonização. Sobre ela declara:

É essa Agencia Official quem vela pela fiel execução do Regulamento para o transporte dos immigrantes; quem inspecciona o serviço da hospedaria, destinada aos recém chegados; quem providencia sobre o seu desembarque e o de suas bagagens; quem lhes assegura a isenção de todos os direitos de importação na Alfândega; quem os interna para os planaltos do interior da provincia do Rio de Janeiro, quando ha epidemias; quem annuncia gratuitamente; os seus serviços quando desejam empregar-se como criados ou como officiaes de officio; quem os

\footnotetext{
${ }^{46}$ Ibid., p. 108, grifo nosso.

${ }^{47}$ CAMPOS, Gustavo Barreto de. Dois séculos de Imigração no Brasil: A construção da imagem e papel social dos estrangeiros pela imprensa entre 1808 e 2015. Tese de Doutorado apresentada a Universidade Federal do Rio de Janeiro (UFRJ). Rio de Janeiro, 2015, p. 183.

${ }^{48}$ MESQUITA, Sergio L. Monteiro. A Sociedade Central de Imigração e a política imigratória brasileira (1883-1910). Dissertação de Mestrado apresentado a Universidade Estadual do Rio de Janeiro (UERJ), 2000, p. 63.

${ }^{49}$ LIMA, op. cit., p. 157.
} 
Revista NEP - Núcleo de Estudos Paranaenses, Curitiba, v.5, n.1, jun. 2019

envia ás Colônias ou ás Províncias que preferem; em fim, quem facilita, em tudo e por tudo, aos immigrantes os primeiros trabalhos de estabelecimento no Brasil ${ }^{50}$.

Documentações concernentes à Agência Oficial de Colonização mostraram-se bastante difíceis de serem encontradas em nossa investigação, Gabler também lidou com tal obstáculo, apontando apenas que o Relatório Ministerial de 1876 a definiu como "uma instituição privada absorvida pelo governo" ${ }^{\text {51 }}$. O relatório diz respeito à união dessa agência com a Comissão do Registro Geral e Estatística das Terras Públicas e Possuídas:

Convinha que estes dous serviços, ligado como são por estreita affinidade, recebessem direcção uniforme e continua, qual podia provir de um centro comum, ampliando-a convenientemente a acção das repartições de caracter provisoerio que nelles superintendiam, regularizando-se e methodizando-se a fiscalização e ao mesmo tempo descentralizando-se o trabalho que a antiga organização impunha á Secretaria de Estado, em detrimento da celebridade dos negócios ${ }^{52}$.

A união desses dois órgãos deu origem à Inspetoria Geral de Terras e Colonização (IGTC). Criada pelo decreto ${ }^{\circ}$ 6129, em 23 de fevereiro de 1876, a Inspetoria veio substituir a Comissão do Registro Geral e Estatística das Terras Públicas e Possuídas ${ }^{53}$ e tinha como funções administrar todos os assuntos referentes à "recepção, agasalho, destino e estabelecimento dos imigrantes", demarcar as terras públicas e dividir os lotes para os imigrantes ${ }^{54}$, bem como resolver os problemas que poderiam surgir nesse espaço entre a chegada do imigrante e sua colocação no núcleo destinado ${ }^{55}$. Para Silva, no entanto, a Inspetoria não conseguiu realizar muito mais do que os órgãos anteriores a ela, o que pode ser justificado pelo relatório do próprio Inspetor Geral, Accioli de Vasconcellos quando declara, em 1888:

Continua esta Inspetoria sem elementos para organizar convenientemente o movimento relativo às legitimações e revalidações de posses, assim como à venda das terras devolutas feitas nas Províncias, por não receber as devidas informações,

\footnotetext{
${ }^{50}$ PARANÁ, op. cit., p. 110

${ }^{51}$ GABLER, op. cit., p. 18.

${ }^{52}$ BRASIL. Relatório do anno de 1876 apresentado a Assembleia Geral Legislativa na $1^{\text {a }}$. Sessão da 16 $^{\text {a }}$. legislatura. Rio de Janeiro: Typographia Perseverança, 1877, p. 402. Disponível em < http://brazil.crl.edu/bsd/bsd/u1962/000003.html>. Acesso em: 10 de jan. de 2019.

53 CARVALHO, José Murilo de. "Modernização Frustrada: A política de terras no Império". Revista Brasileira de História. São Paulo, 1981, n. 1, p. 49.

${ }^{54}$ VASCONCELLOS, F. de B. e Accioli de. O guia do emigrante para o Império do Brazil. Rio de Janeiro, 1884.

${ }^{55}$ SALLES, Maria Izabel Bernardes Moreira. Santana - imigração e colonização (um núcleo paulista de colonização oficial). Dissertação de Mestrado apresentada a Faculdade de Filosofia, Letras e Ciências Humanas (FFLCH-USP). São Paulo, 1978, p. 6.
} 
Revista NEP - Núcleo de Estudos Paranaenses, Curitiba, v.5, n.1, jun. 2019

o que, aliás, não parece difícil ministrar, visto que todos esses trabalhos dependem de uma só repartição ${ }^{56}$.

Outro fato que evidencia a incapacidade da IGTC de cumprir com suas obrigações é sua reorganização, através do Decreto n. 603, de 26 de julho de 1890 . O ato criou a Repartição Central, que teria sua sede na Capital da República, e divisões menores, a níveis estaduais, com essa descentralização os encargos com os serviços imigratórios para a União diminuíram ${ }^{57}$. Essas aferições constatam que, apesar do otimismo visto no relatório de 1876, a IGTC não conseguiu colocar-se em um patamar superior à Agencia Oficial:

No que toca á colonização, reconhecera-se que uma simples agencia, com atribuições limitadas e sem acção própria, subordinada por incessante dependência e privada de toda a iniciativa, não podia satisfazer, senão mui incompletamente, os fins de sua creação [...]

Nos poucos mezes que conta de existencia, bem que sejam ainda insufficientes para por em relevo todas as vantagens e defeitos da reforma, a Inspectoria Geral tem oferecido á administração auxilio eficaz $[\ldots]^{58}$

De volta ao guia, temos, então, os seguintes favores listados: 1) Pagamento da diferença do preço da passagem em relação aos Estados Unidos; 2) Adiantamento do valor total das passagens àqueles que se dirigissem aos núcleos coloniais; 3) Isenção nas taxas de bagagens; 4) Hospedagem no alojamento oficial da Agência.

Em relação à hospedagem, ainda não podemos falar na existência de hospedarias para imigrantes no Paraná, os imigrantes ficavam alojados em grandes barracões, casas ou em qualquer lugar disponibilizado pelo estado ${ }^{59}$. Além disso, diferentemente das medidas adotadas por essas hospedarias, de estadia gratuita, aqui os imigrantes deviam arcar com sua estadia e alimentação, como podemos perceber pelo seguinte trecho:

\footnotetext{
56 VASCONCELLOS, 1889 apud SILVA, Marcio Antônio Both da. "Lei de Terras de 1850: lições sobre os efeitos e os resultados de não se condenar "uma quinta parte da atual população agrícola"”. Revista Brasileira de História. São Paulo, 2015, vol. 35, n 70, p. 90.

${ }^{57}$ IOTTI, Luiza (org.). Imigração e colonização: legislação de 1747-1915. Caxias do Sul: EDUCS, 2001, p. 452.

${ }^{58}$ BRASIL, op. cit., p. 402.

${ }^{59}$ Inicialmente esses locais eram apenas casas alugadas pelo governo, sem condições sanitárias e/ou estruturais para comportar os estrangeiros, o que causou um segundo problema para o Brasil: as denúncias das condições insalubres por parte dos imigrantes para os seus governos eram, muitas vezes, publicadas em jornais, o prejudicava a imagem do país no exterior. KUSHNIR, Beatriz. "A Hospedaria Central: a Ilha das Flores como a ante-sala do Paraíso”. In: MATOS, Maria Izilda, et al. (Org.). Deslocamentos \& Histórias: os portugueses. Bauru: EDUSC, 2008, p. 62.
} 
Hospedagem no Estabeleccimento da Agricultura da Agencia Official de Colonisação, a razão de 800 réis diários por adulto e 500 réis por menor de annos e maior de 9 annos [...] Dá-se-lhe tambem alimentação por dez dias, escrevendo o seu debito em caderneta para ser posteriormente pago ${ }^{60}$

Esse fato demonstra o avanço das políticas imigratórias, que, com o passar dos anos e o aumento do fluxo de pessoas adentrando nossas fronteiras exigiriam instalações adequadas e de qualidade para comportar o estrangeiro. $\mathrm{O}$ surgimento de tais locais para o recebimento de imigrantes não se restringiu ao Brasil, países como Estados Unidos e Argentina também providenciaram seus centros de acolhimento de estrangeiros. No Brasil, a Hospedaria da Ilha das Flores ${ }^{61}$ é classificada como a primeira hospedaria oficial criada pelo governo imperial, contudo, Rosa Guadalupe Udaeta, em Nem Brás, nem Flores, refuta essa afirmação e revela diversos outros edifícios que haviam sido organizados com os mesmos objetivos anteriormente à Flores ${ }^{62}$.

Em vias de conclusão, temos o tópico "Indústrias recomendáveis aos Emigrantes" e, como seu próprio título deixa claro, faz uma relação das melhores opções para o estrangeiro se dedicar. Exatamente com essa perspectiva de aconselhamento que o livro é finalizado, indicando o que o imigrante deveria ou não fazer quando chegasse ao Brasil, para onde deveria se dirigir e o que deveria fazer depois de estabelecido. Como podemos perceber pelo excerto abaixo.

\footnotetext{
Ao partir da Europa com destino á provincia do Paraná, ou a qualquer outra provincia do Império do Brasil ô emigrante deve têr como principal aspiração acquirir uma propriedade territorial nesse prospero e auspicioso paiz. Em viagem deve fortalecer-se nessa aspiração: formar o plano de, apenas chegado, comprar, a dinheiro ou a prazo, um bom lote de terras, e trabalhar para constituil-o um rico patrimônio para si e sua família. Deve varrer de sua mente todas as idéas de minas de ouro e de diamantes; não faltam no Brasil d'essas minas; não são ellas, porém, que fazem a felicidade dosimmigrantes; e que asseguram o porvir de suas familias.

$[\ldots]$

Cumpre que o immigrante se demore o menos possível nas cidades marítimas, onde não faltam sedueções o máos conselhos. Não é essa a oceasião de procurar divertimentos e distracções; mas sim a de tractar de ir plantar, quanto antes, o seu futuro e o de sua família ${ }^{63}$.
}

\footnotetext{
${ }^{60}$ PARANÁ, op. cit., p. 110-111.

${ }^{61}$ A Hospedaria funcionou entre os anos de 1876 até 1966 e desempenhou um importante papel para a política imigratória brasileira, tendo sido a principal referência na recepção, acolhimento e triagem dos imigrantes até o surgimento da Hospedaria do Brás, em São Paulo. REZNIK; FERNANDES, op. cit., p. 248.

${ }^{6}$ UDAETA, Rosa Guadalupe Soares. Nem Brás, nem Flores: Hospedaria de Imigrantes da cidade de São Paulo. Tese de Mestrado apresentada a Faculdade de Filosofia, Letras e Ciências Humanas (FFLCH-USP). São Paulo, 2010.

63 PARANÁ, op. cit., p. 117-118.
} 
Afinal, não podemos nos esquecer que este é um guia para emigrantes e, após se estender por mais de cem páginas com inúmeras informações, nota-se uma mudança na forma como a narrativa é construída, aqui, realmente, notamos um discurso de manual, até então escondido sobre a narração de rios, animais e plantas.

\section{Considerações Finais}

Seguindo o modelo de imigração adotado por outras províncias do Império, o Paraná assumiu o compromisso de "preencher seus vazios" por meio da criação de várias colônias baseadas na pequena propriedade que, por sua vez, deveriam diversificar e abastecer os mercados locais com os gêneros alimentícios. Como demonstra Sérgio Buarque de Holanda, a escassez "dos gêneros de alimentação torna-se tema de todos os relatórios dos presidentes de província durante os anos cinquenta [...]"64. Isto posto, fica claro que Esclarecimentos é fruto desta política emigratória, voltada para assentar estrangeiros em núcleos coloniais.

No entanto, apesar de parecer controverso, o emigrante não se apresenta como o elemento principal nesse guia: esse espaço é ocupado pela agricultura. Novamente, devemos lembrar que, no período de sua confecção e distribuição, a província paranaense passava por uma crise de artigos de subsistência e, também, que o órgão responsável pelo guia, a SENACOP, havia adotado uma política de proteção da lavoura. Essa realidade externa ao guia, nos leva à hipótese de que ele funcionou, primeiramente, como uma ferramenta das políticas que visavam dar estabilidade à agricultura regional, ao mesmo tempo em que atuou como propaganda imigratória, mas de maneira secundária.

Apesar dessas diferentes nuances, a publicação ainda deve ser classificada como um guia para emigrante, afinal, mesmo que este personagem tenha se escondido entre um tema ou outro, a importante relação entre imigração e agricultura ainda se faz presente pelas folhas do livreto, onde ambos se beneficiam do material.

Imigrante e agricultura; agricultura e imigrante. Em uma relação quase simbiótica, esses dois elementos caminham juntos quando tratamos da imigração no século XIX. Propomos, então, a seguinte reflexão: qual fator que vem primeiro, o imigrante ou a

${ }^{64}$ HOLANDA, Sérgio Buarque. "Prefácio". In: DAVATZ, Thomas. Memórias de um colono no Brasil (1850). Belo Horizonte: Itatiaia, 1980, p. 25. 
agricultura? Em São Paulo, por exemplo, a lavoura cafeeira já estava em pleno vigor antes da entrada do estrangeiro, logo, nesse caso, a agricultura vem antes do imigrante.

Agora passemos para o caso do Paraná, onde a política imigratória da região (mesmo que ainda no início) compreendia as deficiências de sua agricultura de subsistência. Dessa maneira, na província paranaense temos o oposto do que ocorreu na província paulista: o imigrante vem antes da agricultura, pois ela simplesmente não existe ou existe de maneira muito precária. O fato desse tipo de agricultura não existir/ser deficiente é, portanto, o motor que move o guia Província do Paraná, dados estatísticos e esclarecimentos para os emigrantes.

\section{Referências Bibliográficas}

BEIGUELMAN, Paula. A formação do povo no complexo cafeeiro: aspectos políticos. São Paulo: Pioneira, 1968.

CAMPOS, Gustavo Barreto de. Dois séculos de Imigração no Brasil: A construção da imagem e papel social dos estrangeiros pela imprensa entre 1808 e 2015. Tese de Doutorado apresentada a Universidade Federal do Rio de Janeiro (UFRJ). Rio de Janeiro: 2015.

CARVALHO, José Murilo de. Modernização Frustrada: A política de terras nos Império. Revista Brasileira de História, São Paulo, n. 1, p. 39-57, 1981.

CHALHOUB, Sidney. Cidade febril: cortiços e epidemias na Corte imperial. São Paulo: Companhia das Letras, 1996.

CHAVES, C. L. Epidemias e imigração: as relações internacionais entre o Império do Brasil e as repúblicas platinas na segunda metade do século XIX. Anais do XXIII Simpósio Nacional de História: história, guerra e paz. Londrina: Editorial Mídia, 2005.

GABLER, Louise. A secretaria de Estado dos Negócios da Agricultura, Comércio e Obras Públicas e a modernização do Império (1860-1891). Rio de Janeiro: Arquivo Nacional, 2012.

HOLANDA, Sérgio Buarque. Prefácio. In: DAVATZ, Thomas. Memórias de um colono no Brasil (1850). Belo Horizonte: Itatiaia, 1980.

IOTTI, Luiza (org.). Imigração e colonização: legislação de 1747-1915. Caxias do Sul: EDUCS, 2001.

KUSHNIR, Beatriz. A Hospedaria Central: a Ilha das Flores como a ante-sala do paraíso. In: MATOS, Maria Izilda Matos, et. al. (Org.). Deslocamentos \& Histórias: os portugueses. Bauru: EDUSC, 2008. 
LAMOUNIER, Maria L. Da escravidão ao trabalho livre (A lei de locação de serviços de 1879). Campinas, SP: Papirus, 1988.

LESSER, Jeffrey. A invenção da brasilidade. Identidade nacional etnicidade e políticas de imigração. São Paulo: Editora Unesp, 2015.

MACCARI JUNIOR, Agenor. Análise do pré-processamento da erva-mate para chimarrão. Campinas, SP, 2005.

MANFROI, Olívio. A colonização Italiana no Rio Grande do Sul. Implicações Econômicas, Políticas e Culturais. Porto Alegre: Fotogravura do Sul Ltda. 1975.

MEIRA, Roberta B. Um olhar para a lavoura: os relatórios do Ministério dos Negócios da Agricultura, Comércio e Obras Públicas e dos Presidentes de Província no final do Império. Revista Eletrônica Documento/Monumento, 2009.

MENDES, José Sacchetta Ramos. Desígnios da Lei de Terras: imigração, escravismo e propriedade fundiária no Brasil Império. Salvador, 2009.

MESQUITA, Sergio L. Monteiro. A Sociedade Central de Imigração e a política imigratória brasileira (1883-1910). Dissertação de Mestrado apresentado a Universidade Estadual do Rio de Janeiro (UERJ). 2000.

MORAES, Fábio F. Expansão do mercado e da produção: o auge do mate catarinense. Anais do VIII Encontro de Economia Catarinense. Rio do Sul (SC), 2014. v. 1.

PEREIRA, Magnus R. Semeando iras rumo ao progresso. Ordenamento jurídico e econômico da sociedade paranaense (1829-1889). Curitiba: UFPR. 1992.

PRIORI, A., et al. História do Paraná: séculos XIX e XX [online]. Maringá: Eduem, 2012,

REZNIK, Luís; FERNANDES, Rui A. N. Hospedarias de Imigrantes nas Américas: a criação da hospedaria da Ilha das Flores. História (São Paulo. Online), 2014.

SALLES, Maria Izabel Bernardes Moreira. Santana - imigração e colonização (um núcleo paulista de colonização oficial). Dissertação de Mestrado apresentada a Faculdade de Filosofia, Letras e Ciências Humanas (FFLCH-USP). São Paulo, 1978.

SALOMON, Marlon. O clima, a Imigração e a Invenção do Sul do Brasil no século XIX. In: ARRUDA, Gilmar (org.). Natureza, fronteiras e território. Londrina: Eduel, 2013.

SILVA, Marcio Antônio Both da. Lei de Terras de 1850: lições sobre os efeitos e os resultados de não se condenar "uma quinta parte da atual população agrícola". Revista Brasileira de História. São Paulo, 2015, vol. 35, nº 70.

UDAETA, Rosa Guadalupe Soares. Nem Brás, nem Flores: Hospedaria de Imigrantes da cidade de São Paulo. Dissertação de Mestrado apresentada a Faculdade de Filosofia, Letras e Ciências Humanas (FFLCH-USP). São Paulo, 2010.

Fontes 
Revista NEP - Núcleo de Estudos Paranaenses, Curitiba, v.5, n.1, jun. 2019

BRASIL. Relatório do anno de 1876 apresentado a Assembleia Geral Legislativa na 1a. Sessão da 16 . legislatura. Rio de Janeiro: Typographia Perseverança, 1877.

PARANÁ. Provincia do Paraná, dados estatisticos e esclarecimentos para os emigrantes. Rio de Janeiro: G. Leuzinger \& Filhos, 1875.

VASCONCELLOS, F. de B. e Accioli de. O guia do emigrante para o Império do Brazil. Rio de Janeiro, 1884.

Recebido em: 11 mar. 2019.

Aceito em: 14 jun. 2019. 